\title{
A Study on Patent Valuation Factors
}

\section{Guozhong $\mathrm{Li}^{1}$ and Seong-Taek Park ${ }^{2}$}

${ }^{1}$ Dept. of Management Science and Information System, Faculty of Management and Economics, Kunming University of Science and Technology, 650093, China

${ }^{2}$ Dept. of Management Information System, Chungbuk National University, 28644, Korea

\begin{abstract}
Background/Objectives: The purpose of this study is to examine the factors of patent value evaluation at home and abroad, and to derive common factors of patent evaluation. Methods/Statistical analysis: In this paper, we present the evaluation factors suggested by the past research and select some common factors. Findings: Since different factors are used to evaluate the value of a patent by each institution, the evaluation results differ from institution to institution. Therefore, we examined the evaluation models of two Korean institutions and three evaluation models overseas institutions. Through this, we derive the patent valuation factors which are commonly used by 5 institutions. The fact that the 14 patent valuation factors are frequently used seems to imply the importance of them. Improvements/Applications: The derived factors are expected to be useful for future patent valuation.
\end{abstract}

\section{Index Terms}

Patent, Patent valuation, Valuation, IPR, Valuation Factor

\footnotetext{
Corresponding author : Guozhong Li

147508114@qq.com

- Manuscript received November 20, 2017.

- Revised December 6, 2017 ; Accepted December 8, 2017.

- Date of publication December 31, 2017.

(C) The Academic Society of Convergence Science Inc.

2546-1583 $\odot 2017$ IJEMR. Personal use is permitted, but republication/redistribution requires IJEMR permission.
} 


\section{INTRODUCTION}

In the knowledge economy, the importance of intellectual property is well recognized because of its impact on the corporate competitiveness. Intellectual property involving patent is considered much valuable in association with the business strategy and the technology strategy. Moreover, the advanced countries and their multinationals create and maintain the hegemony in world economy by strategically protecting their intellectual property.

Intellectual property can be said to be 'a creator and protector' of corporate competitiveness. Multinationals can continue to improve and maintain their competitive edge by strategically taking advantage of their know-hows to develop quality products and services for the monopolistic position in the market. Also they employ appropriate patent strategy to expand and maintain their market clouts. Thus, patent plays a pivotal role in developing corporate competitiveness as well as a nation's prosperity.

In the knowledge economy, production elements such as know-how or technology contribute more to value creation than traditional production elements do. As such, there are more active trades of those intellectual production elements. For instance, financial institutions that lend to or invest in corporations are beginning to put more importance on the intangible assets in figuring out the corporate values [1].

Proper valuation of patents helps activate the technology trade market and it grows rapidly. Companies might buy necessary technologies for themselves and sell or license their technologies to other companies. Sometimes companies encounter difficult decisions of choosing between the commercialization of their technologies on their own and selling the technologies to others. In order to make informed decisions regarding technology transactions, companies need objective evaluation of technologies.

There have been measurable research efforts to figure out the impact of patent acquisition on stock prices or to analyze the relationship between patent ownership and corporate value. Researchers have often used the number of patents to measure the value of a company's intellectual property. Since each patent has its own value different from other patents, various patent-based measures such as the weighted citation frequency of the patent [2], the number of years renewed for the patent $[3,4]$, the scale of patent group that is the number of countries which grant the patent [5], and the number of claims [6] are incorporated.

Chiu and Chen [7] used AHP method to evaluate and select the most promising, i.e., valuable, patented technology for a new MP3 product. Their research is focused on figuring out the relative importance of a patent rather than its monetary value which is almost impossible to measure accurately.

Since the importance of patent valuation is well recognized, a number of valuation methods are suggested by researchers, most of which are based on the intangible asset evaluation approach, such as the cost approach, the market approach and the income approach [8].

In this paper, we present the evaluation factors suggested by the past research and select some common factors. Thus we can find the valuation factors that have more significant influence on patent value, which is a main contribution of this article. Also we plan to use those common valuation factors for a future research on patent valuation in several product categories. The aim of the future research is to find out which evaluation factors are considered relatively more important than other evaluation factors in evaluating a patent value in a certain product category. In other words, we are interested in figuring out the relative importance of the evaluation factors in a product category. We plan to conduct surveys for several product categories such as electronics, pharmaceuticals, machinery, etc.

\section{LITERATURE REVIEW}

\section{A. Intellectual Property}

Intellectual property (IP) refers to creations of the mind: inventions, literary and artistic works, and symbols, names, images, and designs used in commerce.

Intellectual property is divided into two categories: Industrial property, which includes inventions (patents), trademarks, industrial designs, and geographic indications of source; and Copyright, which includes literary and artistic works such as novels, poems and plays, films, musical works, artistic works such as drawings, paintings, photographs and sculptures, and architectural designs. Rights related to copyright include those of performing artists in their performances, producers of phonograms in their recordings, and those of broadcasters in their radio and television programs. For an introduction to IP for non-specialists see [9].

\section{B. Patent valuation}

\subsubsection{Understanding of patent valuation}

Similar to technology valuation, patent valuation generally begins by covering the technology's technical and commercial aspects. From an intrinsic 
perspective, patent valuation is based on the principle of technology valuation. This is due to the fact that the technology valuation's decision-making process and its principle and real-life applications reflect much of that are required for patent valuation [10]. Thus, further study is required regarding technology valuation and its underlying principle.

\subsubsection{Principle of technology valuation}

\section{(1) Target of technology valuation}

Technology is the target of technology valuation. This section defines the meaning and scope of technology and presents the target technology suitable for efficient technology valuation.

Capon \& Glazer [11] defined technology as knowhow, more specifically with respect to a firm, as the information required to produce and/or sell a product or service.

They identified three components of know-how as product technology, process technology and business method. The product technology is the set of ideas embodied in the product. The process technology is the set of ideas involved in the manufacture of the product or the steps necessary to combine new materials to produce a finished product. The business method is the set of management procedures associated with selling the product and administration of the business unit.

Boer [12] addressed that technology is the application of knowledge to useful objectives. It is usually built on previous technology by adding new technology inputs or new scientific knowledge. The criterion for successful technology is usefulness. In many cases, usefulness does not require that the user understand the technology. In contrast, science is not very useful to people who lack science training. This criterion is helpful in distinguishing science from technology. Technology also differs from science in the fact that technology inevitably becomes obsolete.

As defined above, the technology must possess 'commercial value' to be considered for valuation. In other words, the technology must hold value in the form of tradable product or create added value in conjunction with a type of service. Thus, it would be meaningless to discuss technology that cannot be used in a product or a service from a business standpoint.

Technology holds value as an asset so it is represented as an intangible asset in an accounting ledger. Technology intangible asset consists of patents, patent-able inventions, mask works, trade secrets, know-how, confidential information, computer software, database, and copyrightable materials such as operation manuals. Intangible assets whose rights are recognized and protected by law are called intellectual property.

Intellectual properties include trademarks, copyrights, creative types such as computer software, industrial design, and innovative types such as sales secrets.

Also, intellectual property is divided into five categories like market-related, technology-related, artistic-related, data processing-related, and engineering-related types.

Since most technology intangible assets are recognized and protected by law for a certain period of time, such assets can be considered as intellectual property. Companies for practical purposes categorize technology as generic, basic, and key technologies. Generic technology is common technology such as conveyor belts with widespread use while basic technology provides strategic advantage or flexibility (e.g. Point-of-sales system). Such technologies can be mainly acquired from products and systems in related markets or specialized companies.

However, key technologies, being proprietary and indigenous, contribute significantly as a strategic weapon for a company to maintain its competitive advantage.

Since products (or parts or systems) consisting of generic and basic technology are most likely available to many suppliers, prices of such products are decided more by market mechanism rather than technology. Therefore, in the above case, competitive advantage is not derived from technology superiority but from other productionrelated factors such as cheaper raw materials or management, production, and operation know-how. And it is acceptable to assume that no rent can be earned from generic and basic technology so the value of such technologies can be seen as 'zero'.

But products (or parts or systems) combined with key technologies are definite targets for technology valuation and the value of the product is equal to the value of the key technology of the product. But when considering such product, valuation differs depending on whether it is a final product or in $R \& D$ stages. If the product consists of multiple key technologies, the value of each key technology can be measured once the valuation process of the product is complete.

Meanwhile, for venture capital funded start-up companies which derive most of its value from one or two technologies or products only, company valuations can serve as substitutes for technology or product valuations. Thus targets of technology valuation in this case will consist of $R \& D$ projects, 
products, key technologies, and venture capital funded start-up companies.

(2) Technology valuation and assessment

In order to differentiate technology valuation from technology assessment, the study shall define technology assessment first. The key to formulating an effective business strategy is to clearly determine the organization's resources and environment. Given that technology assessment takes place from a strategic perspective, technology assessment decides which technology asset creates the strategic advantage and further what resources are expended to support the company's business strategy. Secondly, it determines which technology trends will affect the company's competitive strategy. At this point, the company's resources and timeline are evaluated from a flexibility standpoint and technological trends can be derived through technology forecasting.

Since technology assessment is strategy-oriented, the standard for evaluation is based on how much strategic value it provides to the company. In the meantime, technology valuations are generally independent from company strategy. For technology valuation, the fair market value of the technology itself is important and the focus is on estimating the technology's monetary value from a neutral, arm's length transaction situation [13].

\subsubsection{Preceding research of patent valuation}

Existing valuation methods such as cost approach, market approach, income approach, and discounted cash flow (DCF) methods have been used for patent valuation as well. However, such methods have shown a limit on measuring the economic benefit of intangible assets as shown from significantly different results from each method and they focus mainly on quantitative figures and cannot encompass the overall value of the patents. Output data from the above methods are used for technology transaction or information for security purposes and are limited in their uses as information for key business initiatives such as business strategy formulation and patent infringement suits.

In response, Bae [14] explores a new patent valuation method using a patent map. As part of the patent map analysis, application method, family patent method, contour method, etc. were used to develop a new technology valuation method to measure the value of intangible assets.

Yeon [6] analyzes patents' influences on listed Korean companies ' market capitalization through event study and panel analysis methods. Event study method focused on how patent acquisition disclosure impacted that day's stock value and analysis has shown that patent acquisition has a positive impact on stock value. And the rise in value holds steady for a long period of time following the patent acquisition.

And analysis of annual panel documents have shown patent acquisition has a lasting positive effect on the market value of companies.

Cho [15] applies the QFD (Quality Function Development) method to derive important factors for patent valuation and uses such factors to analyze patents.

The study minimized the forecast error when applying the patent analysis output on a quantitative technology valuation model and used the model on business cases. To determine the relative importance between the factors, the study used the AHP (Analytic Hierarchy Process). Also, United State's National Technology Transfer Center's (NTTC) 10 value factors and QFD methods were used to help derive the key patent valuation factors.

Cho [1] stresses that when valuing patents, it is important to consider the special nature of patents and reviews patent licensing and utilization of valuation methods.

\section{Patent valuation factors}

\section{A. patent valuation methods}

Patent valuation methods can be largely divided into qualitative and quantitative types. Qualitative methods can be further divided into expert judgment, intuition, surveys, comparison through focused group interview method, and Delphi methods. Quantitative methods include scoring, rating, and absolute sizing through relative comparison. Quantitative approach for patent valuation include technology scoring, scale model, and accounting or monetary value model.

\section{B. Application of Patent Valuation Factors}

The most commonly used patent valuation methods include scoring, comparison, expert judgment, and Delphi methods and added weight is applied to the final score accordingly.

Table 1. DOMESTic(Korea) Patent VALUATION FaCtors

\begin{tabular}{lll}
\hline FACTORS & \\
\hline KIPA & Alternative & Barriers to \\
& technologies & commercialization \\
& Complexity of & Capital Required for \\
technology & implementation \\
& Cost to avoid or & Company \\
\hline
\end{tabular}




\begin{tabular}{ll}
\hline engineer around & expectation \\
Differentiation & Competitive response \\
Geographic area & Competitor impact \\
Insurance value & Customer effect \\
Intellectual & Customer willingness \\
property costs & to pay \\
Legal strength & Derivation sales \\
Obsolescence & Displacement \\
potential & potential \\
Ongoing & Expected revenue \\
technology & Impact on other \\
outlook & products \\
Pioneering & Nature of expected \\
technology & revenue \\
Special & Right to use \\
credentials & technology \\
obtained & Royalty rates \\
Special & Time required for \\
Credentials & implementation \\
obtained & Useful economy life \\
Stage of the & Usefulness to others \\
technology & Usefulness to user \\
Strategic & \\
positioning & \\
Uniqueness of & \\
commercial & \\
advantage & \\
Alternative & Barriers to \\
technologies & commercialization \\
Complexity of & Competitive response \\
technology & Competitor impact \\
Degree of & Derivation sales \\
competition & Displacement \\
Differentiation & potential \\
Imitation of & Expected revenue \\
technology & Impact on other \\
Pioneering & products \\
technology & Nature of expected \\
Quality of & revenue \\
technology & Time required for \\
Royalty rates & implementation \\
Stage of the & Useful economy life \\
\hline \hline & \\
\hline technology & \\
\hline
\end{tabular}

From these, scoring valuation method has the most widespread use and after itemizing evaluation factors, scoring is done by either straight addition, addition with weight factor, continual, and iterative approaches [16]. After comparing various valuation methods, Japanese Mitsubishi R\&D institute has concluded that scoring valuation method is the most superior based on its practicality and effectiveness with applicability across a far spectrum [17].
Also, checklist method consists of a quantitative checklist to indirectly measure the technology's value. Although principle behind the checklist method is very similar to that of the scoring valuation, it is more relatively more complex and detailed.

And scoring valuation is very standardized as opposed to checklist method where the measurement index and unit varies depending on the technology or the focus of the valuation [18]. After reviewing quantitative approaches that include technology scoring, scale model, and accounting or monetary value model, the appropriate methods for patent valuation appears to be scoring valuation and checklist methods [17].

The following section will review domestic and international valuation models and examine factors that affect patent valuation.

Table 2. INTERNATIONAL PATENT VALUATION FACTORS

\begin{tabular}{lll}
\hline \hline FACTORS & & \\
\hline NTTC & Barriers to & Alternative \\
commercialization & technologies \\
Capital Required & Competitive \\
for & response \\
implementation & Competitor impact \\
Company & Complexity of \\
expectation & technology \\
Cost to avoid or & Differentiation \\
engineer around & Displacement \\
Customer effect & potential \\
Customer & Geographic \\
willingness to pay & Insurance value \\
Derivation sales & Legal strength \\
Expected revenue & Obsolescence \\
Impact on other & potential \\
products & Strategic \\
Intellectual & positioning \\
property costs & Uniqueness of \\
Nature of & commercial \\
expected revenue & advantage \\
Ongoing & \\
technology & \\
outlook & \\
Pioneering & \\
technology & \\
Royalty rates & \\
Special & \\
credentials & \\
obtained & \\
Stage of the & \\
technology & \\
Time required for & \\
implementation & \\
Useful economy & \\
life & \\
& \\
& \\
& \\
& \\
& \\
& \\
& \\
& \\
& \\
& \\
& \\
& \\
& \\
& \\
& \\
& \\
& \\
&
\end{tabular}




\begin{tabular}{|c|c|c|}
\hline & $\begin{array}{l}\text { Usefulness to } \\
\text { others } \\
\text { Usefulness to user }\end{array}$ & \\
\hline $\begin{array}{l}\text { Dow } \\
\text { Chemical }\end{array}$ & $\begin{array}{l}\text { Alternative } \\
\text { technologies } \\
\text { Complexity of } \\
\text { technology } \\
\text { Legal strength } \\
\text { Patent learning } \\
\text { value } \\
\text { Pioneering } \\
\text { technology } \\
\text { Special } \\
\text { credentials } \\
\text { obtained } \\
\text { Stage of the } \\
\text { technology } \\
\text { Technology value } \\
\text { in use } \\
\text { Uniqueness of } \\
\text { commercial } \\
\text { advantage }\end{array}$ & $\begin{array}{l}\text { Barriers to } \\
\text { commercialization } \\
\text { Capital Required } \\
\text { for implementation } \\
\text { Competitive } \\
\text { response } \\
\text { Competitor impact } \\
\text { Customer effect } \\
\text { Customer } \\
\text { willingness to pay } \\
\text { Nature of expected } \\
\text { revenue } \\
\text { Strategic } \\
\text { positioning } \\
\text { Time required for } \\
\text { implementation }\end{array}$ \\
\hline TVMS & $\begin{array}{l}\text { Alternative } \\
\text { technologies } \\
\text { Complexity of } \\
\text { technology } \\
\text { Pioneering } \\
\text { technology } \\
\text { Special } \\
\text { credentials } \\
\text { obtained } \\
\text { Stage of the } \\
\text { technology } \\
\text { Technology } \\
\text { application } \\
\text { Technology } \\
\text { completion } \\
\text { Uniqueness of } \\
\text { commercial } \\
\text { advantage }\end{array}$ & $\begin{array}{l}\text { Competitive } \\
\text { response } \\
\text { Competitor impact } \\
\text { Differentiation } \\
\text { Legal strength } \\
\text { Positioning of } \\
\text { technology } \\
\text { Strategic } \\
\text { positioning } \\
\text { Uniqueness of } \\
\text { commercial } \\
\text { advantage }\end{array}$ \\
\hline
\end{tabular}

\section{Analysis of Patent Valuation Models}

This study examined the following studies: Korean Technology Exchange ' s technology competitiveness evaluation checklist model, Korean Invention Promotion Association's patent valuation model, NTTC(National Technology Transfer Center)'s Top Index Model, DOW Chemical's TF method model, and TVMS (Technology Valuation Management System) model.

Korean Technology Transfer Center and Korean Invention Promotion Association are Korean 's leading organizations for technology valuation and also carry out patent valuation. Also NTTC, DOW Chemical, and TVMS are leading international organizations for technology valuation and since many Korean organizations base valuation models after the NTTC model, the international models have been included in the study.

The above valuation models have varying evaluation factors depending on the organization's purpose.

And the categories are arranged in a very differing way. After analyzing the above 5 technology valuation models, the key valuation factors are shown in Table 1 and 2.

\section{Deriving Patent Valuation Factors}

Study of related literature to derive patent valuation factors and structure has defined patent valuation as follows. Patent valuation is intangible not tangible property, thus harder to measure the value compared to tangible goods.

Patents are intangible technology asset and from a technology standpoint, it represents the source of its value. So based on valuation models from 5 organizations, this study focused on identifying valuation standards and factors under the patent valuation principles. We identified the 14 valuation factors which appear most frequently in the 5 valuation models. The result is shown in Table 3.

Table 3. DERIVING PATENT VALUATION FACTORS

\begin{tabular}{ll}
\hline \hline FACTORS & \\
\hline Alternative & Barriers to \\
technologies & commercialization \\
Complexity of & Competitive response \\
technology & Competitor impact \\
Differentiation & Legal strength \\
Pioneering & Nature of expected \\
technology & revenue \\
Special credentials & Royalty rates \\
obtained & Time required for \\
Stage of the & implementation \\
technology & \\
Strategic & \\
positioning &
\end{tabular}

\section{CONClusion}

In this paper, we present a literature survey on the past research of the patent valuation factors to find some common factors which have more significant influence on the patent value. Since a value of a patent stems from the technology protected by the patent, it should be noted that we often referred to past research on technology valuation. We studied 
the technology valuation factors that are used by the 5 organizations which evaluate patents. From those patent valuation factors, we identified the 14 valuation factors which are most frequently used by the valuation models employed by the organizations. The fact that the 14 patent valuation factors are frequently used seems to imply the importance of them. It is our expectation that those patent valuation factors can be used in a standard scheme of patent valuation. We plan to use those common valuation factors for a future research on patent valuation in several product categories.

A limitation of this research is that we used only the frequency of the valuation factors' appearances as a criterion for selecting the 14 valuation factors. Even though the frequency is an objective selection criterion, it lacks reflecting the opinion or judgement of patent experts which are highly respected and influential in the patent field. Through their long experiences in the field, the experts get equipped with insight and intuition on the value of a patent. Our research could have provided more persuasive results if we had conducted an interview or other empirical study on the expert opinions.

Using the selected patent valuation factors, we plan to advance our research further to figure out the relative importance or weight of each factor. We feel that a factor's relative importance varies according to the category of a product for which the technology of the patent would be used. We plan to conduct surveys for several product categories such as electronics, pharmaceuticals, machinery, etc.

\section{REFERENCES}

[1] Cho, S.Y. (2008). A Study on the Valuation of Patent and its Application for Patent Licensing, Chungnam National University, MA, Korea.

[2] Trajtenberg, M. (1990). Economic analysis of product innovation: The case of CT scanners (Vol. 160). Harvard University Press.

[3] Pakes, A. (1984). Patents as options: Some estimates of the value of holding European patent stocks.

[4] Schankerman, M., \& Pakes, A. (1985). Estimates of the Value of Patent Rights in European Countries During thePost-1950 Period.

[5] Putman, S. (1996). Extending DRAM model: Theorypractice nexus. Transportation Research Record: Journal of the Transportation Research Board, (1552), 112-119.

[6] Yeon, T.H. (2004). Market Evaluation of the Value of Patent. KDI Policy Research, 26(2), Seoul, Korea.

[7] Chiu, Y. J., \& Chen, Y. W. (2007). Using AHP in patent valuation. Mathematical and Computer Modelling, 46(7-8), 1054-1062.

[8] Lee, S.J. (2008). Study on Technology Valuation for the Patent Strategy, Chungbuk National University, MA, Korea.

[9] http://www.wipo.int

[10] Pratt, S. P. (1986). Valuing small businesses and professional practices. McGraw-Hill Professional Publishing.
[11] Capon, N., \& Glazer, R. (1987). Marketing and technology: a strategic coalignment. The Journal of Marketing, 1-14.

[12] Boer, F. P. (1999). The valuation of technology: Business and financial issues in R\&D (Vol. 1). Wiley.

[13] Kim, H.G. (2002). A new Study on patent valuation. Intellectual Property 21, 19-35, Seoul, Korea.

[14] Bae, S.H. (2007). A Case Study of Patent Map Use in Technology Valuation. Chungnam National University, MA, Korea.

[15] Cho, C.H. (2001). An Application of Patent Analysis to the Method of Quantitative Technology Valuation. Ajou University, MA, Korea.

[16] Won, J.W., Jeon, H.S., \& Park, T.W. (2002). Theory Study on Patent Valuation Methodology. Journal of Technology Innovation, 10(2), Seoul, Korea.

[17] Park, S.Y. (2004). A Study on Patent Technology Value Factor. Intellectual Property Research, 2(1), Seoul, Korea.

[18] Park, Y.T. (2001). Study on Technology Valuation Methodology for high technology. KISTEP Research Paper, Seoul, Korea. 